\title{
INTERAÇÃo ENTRE HERBICIDA E INSETICIDA SOBRE O MILHO-PIPOCA (Zea mays), as Plantas Daninhas e a LagaRTA-Do-CaRTUChO ${ }^{1}$
}

\author{
Interaction Between Herbicide and Insecticide on Popcorn (Zea mays), Weeds and Fall \\ Armyworm
}

\author{
SILVA, A.A. ${ }^{2}$, JAKELAITIS, A. ${ }^{3}$, FREITAS, F.M. ${ }^{4}$, FERREIRA, L.R. ${ }^{2}$ e VIVIAN, R. ${ }^{4}$
}

\begin{abstract}
RESUMO - O objetivo deste trabalho foi avaliar o efeito da mistura de herbicidas nicosulfuron + atrazine e o inseticida chlorpirifos sobre o cultivar de milho-pipoca UFVM2, as plantas daninhas e a lagarta-do-cartucho. Utilizou-se o delineamento experimental de blocos completos ao acaso, em esquema fatorial $(5 \times 2)+3$, com quatro repetições. O primeiro fator foi constituído

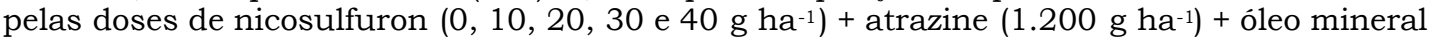
(900 $\left.\mathrm{g} \mathrm{ha}^{-1}\right)$ e o segundo pelas doses do inseticida chlorpirifos $\left(0 \mathrm{e} 240 \mathrm{~g} \mathrm{ha}^{-1}\right)$. Foram avaliados três tratamentos adicionais: duas testemunhas, com e sem capina, ambas sem inseticida, e uma testemunha com capina e com inseticida. Não se observou interação significativa entre doses de nicosulfuron e do chlorpirifos no controle da lagarta-do-cartucho. A mistura no tanque formada pelo chlorpirifos com os herbicidas promoveu intoxicação às plantas de milhopipoca, principalmente nas maiores doses do nicosulfuron $\left(20,30\right.$ e $\left.40 \mathrm{~g} \mathrm{ha}^{-1}\right)$. O chlorpirifos não interferiu na eficiência de controle de plantas daninhas pelos herbicidas nem no estande final, no número de espigas por planta, no rendimento e na capacidade de expansão dos grãos de milho-pipoca.
\end{abstract}

Palavras-chave: chlorpirifos, atrazine, nicosulfuron.

\begin{abstract}
This study aimed to evaluate the effect of the tank-mixture herbicide nicosulfuron combined with the insecticide chlorpirifos on the popcorn cultivar UFVM2, weeds and fall armyworm. The experiment was arranged in a randomized complete block design, in a $(5 \times 2)+3$ factorial scheme and four replications. The first factor consisted of nicosulfuron doses $(0,10$, 20, 30, and $\left.40 \mathrm{~g} \mathrm{ha}^{-1}\right)+$ atrazine $\left(1.200 \mathrm{~g} \mathrm{ha}^{-1}\right)+$ oil $\left(900 \mathrm{~g} \mathrm{ha}^{-1}\right)$ and the second of doses of the insecticide chlorpirifos $\left(0\right.$ and $\left.240 \mathrm{~g} \mathrm{ha}^{-1}\right)$. Three additional treatments were evaluated: two controls, with and without weeding, both without insecticide, and one control with weeding and insecticide. The interaction between the nicosulfuron and chlorpirifos doses in the control of the fall armyworm was not significant. The tank-mixture formed by the chlorpirifos and herbicides caused intoxication to popcorn plants, mainly at nicosulfuron rates $\left(10,20\right.$ and $\left.40 \mathrm{~g} \mathrm{ha}^{-1}\right)$. Chlorpirifos did not interfere in herbicide efficiency in controlling weed, nor in the final stand, number of ears, and production and expansion capacity of the popcorn grains.
\end{abstract}

Keywords: chlorpirifos, atrazine, nicosulfuron.

\section{INTRODUÇÃO}

O controle químico de plantas daninhas na cultura do milho tem se destacado pela eficiência promovida, rapidez na operação e redução nos custos; entretanto, a eficácia dos herbicidas é variável e dependente das condições ambientais, da época de aplicação e da espécie daninha a ser controlada (Merotto Jr. et al., 1997). Dentre os herbicidas recomendados

Recebido para publicação em 3.8.2006 e na forma revisada em 27.2.2007.

Professor Associado do Dep. de Fitotecnia da Universidade Federal de Viçosa - UFV, 36570-000 Viçosa-MG <aasilva@ufv.br>. Professor do Dep. de Agronomia da Universidade Federal de Rondônia - UNIR, 78987-000 Rolim de Moura-RO. ${ }^{4}$ Doutorando em Titotecnia,Escola Superior de Agricultura “Luiz de Queiroz”-ESALQ/USP, 13418-900 Piracicaba-SP, <agrovivian@ yahoo.com.br〉. 
para a cultura do milho e que são utilizados em milho-pipoca em aplicações de pós-emergência, destacam-se o atrazine e o nicosulfuron (Kawazaki, 2001). O atrazine, pertencente ao grupo químico das triazinas, é inibidor da fotossintese e controla espécies daninhas dicotiledôneas e algumas gramineas anuais, podendo ser aplicado em pré e pós-emergência das plantas daninhas, enquanto o nicosulfuron - do grupo químico das sulfoniluréias - é utilizado principalmente em aplicações em pós-emergência no controle de gramíneas e algumas dicotiledôneas (Rodrigues \& Almeida, 2005).

Os cultivares de milho podem apresentar sensibilidade diferencial às sulfoniluréias, dependendo do estádio de desenvolvimento da planta, do ambiente e da dose utilizada (Gubbiga et al., 1995). Trindade (1995), avaliando a interação entre doses de nicosulfuron e cultivares de milho-pipoca, não verificou efeito entre doses e cultivares, mas observou toxidez aos cultivares à medida que se aumentavam as doses do herbicida.

A seletividade das plantas às sulfoniluréias é dada pelas diferentes taxas de metabolização e pela velocidade de absorção e translocação desses herbicidas. Segundo Brow (1990) e Fonne-Pfister et al. (1990), as espécies tolerantes metabolizam rapidamente esses herbicidas, inativando-os por meio do sistema enzimático citocromo $\mathrm{P}_{450}$ monoxigenase, em reações de hidroxilação e glicosilação. Em aplicações do nicosulfuron em mistura com inseticidas temse observado ocorrência de injúrias em plantas de milho, podendo estar associadas à inibição da hidroxilação do nicosulfuron ou ao aumento da absorção e translocação do herbicida pelas plantas (Porpiglia et al., 1990; Moreland et al., 1993). Maiores índices de injúria têm sido verificados quando o nicosulfuron é aplicado em plantas de milho oriundas de sementes tratadas com inseticidas organofosforados (Lithe et al., 1992).

Os sintomas decorrentes da intoxicação podem variar desde a descoloração temporária das folhas até o retorcimento da planta, a paralisação do crescimento e a queda do rendimento de grãos. Essas observações foram confirmadas por Stall \& Bewick (1992), que, avaliando a resposta de três cultivares de milho-doce à dose de $36 \mathrm{~g} \mathrm{ha}^{-1}$ de nicosulfuron, verificaram, no tratamento em que também foi aplicado o inseticida terbufos na dose de $14,5 \mathrm{~kg} \mathrm{ha}^{-1}$, que houve redução significativa da produção em todos os cultivares testados.

O objetivo deste trabalho foi avaliar o efeito da mistura entre os herbicidas nicosulfuron e atrazine e o inseticida chlorpirifos sobre o cultivar de milho-pipoca UFVM2 e a eficiência de controle de plantas daninhas e da lagartado-cartucho.

\section{MATERIAL E MÉTODOS}

O experimento foi realizado em CoimbraMG sobre Argissolo Vermelho Amarelo câmbico, com classificação textural franco-argiloarenosa. A análise química do solo apresentou pH em água de 5,3, CTC (T); soma de bases, $\mathrm{H}+\mathrm{Al}$, Ca e Mg de 6,22; 2,26; 3,96; 1,6; e $0,5 \mathrm{cmol}_{c} \mathrm{dm}^{-3}$, respectivamente; $\mathrm{P}$ e $\mathrm{K}$ de 13,7 e $63 \mathrm{mg} \mathrm{dm}^{-3}$; e $2,76 \mathrm{dag} \mathrm{kg}^{-1}$ de matéria orgânica.

Utilizou-se o sistema convencional de plantio, com uma aração e duas gradagens, realizadas sete dias antes da semeadura. O cultivar UFVM2 foi semeado em novembro de 2002, no espaçamento de $1,0 \mathrm{~m}$ entre linhas. A adubação de plantio constou de $300 \mathrm{~kg} \mathrm{ha}^{-1}$ da formulação 8-28-16 $\left(\mathrm{N}-\mathrm{P}_{2} \mathrm{O}_{5}{ }^{-}\right.$ $\mathrm{K}_{2} \mathrm{O}$ ) e cobertura de $70 \mathrm{~kg} \mathrm{ha}^{-1}$ de $\mathrm{N}$, aplicados na forma de uréia aos 30 dias após o plantio.

O delineamento experimental foi o de blocos ao acaso, em esquema fatorial $5 \times 2+3$, com quatro repetições. O primeiro fator foi constituído pelas doses de nicosulfuron $(0,10,20$, 30 e $\left.40 \mathrm{~g} \mathrm{ha}^{-1}\right)+$ atrazine $\left(1.200 \mathrm{~g} \mathrm{ha}^{-1}\right)+$ óleo mineral (900 $\left.\mathrm{g} \mathrm{ha}^{-1}\right)$, e o segundo, pelas doses do inseticida chlorpirifos (0 e $240 \mathrm{~g} \mathrm{ha}^{-1}$ ). Foram avaliados três tratamentos adicionais: duas testemunhas, com e sem capina, ambas sem inseticida, e uma testemunha com capina e com inseticida. As parcelas experimentais foram constituídas de cinco fileiras de $6,0 \mathrm{~m}$ de comprimento, perfazendo uma área total de $30 \mathrm{~m}^{2}$, sendo as avaliações feitas em área útil de $12 \mathrm{~m}^{2}$.

As aplicações dos herbicidas e do inseticida foram realizadas aos 25 dias após a emergência (DAE) das plantas de milho, utilizando-se pulverizador costal pressurizado com $\mathrm{CO}_{2}$, mantendo a pressão constante de $3,0 \mathrm{kgf} \mathrm{cm}^{-2}$, 
equipado com cinco bicos XR 110.02 espaçados de $0,5 \mathrm{~m}$, aplicando-se o equivalente a $200 \mathrm{~L} \mathrm{ha}^{-1}$ de calda. Na ocasião, o milho se encontrava com quatro a cinco folhas e as monocotiledôneas infestantes, com um a dois perfilhos. As condições no momento da aplicação dos tratamentos foram de céu claro, velocidade do vento inferior a $5 \mathrm{~km} \mathrm{~h}^{-1}$, temperatura do ar de $25{ }^{\circ} \mathrm{C}$ e umidade relativa média de $90 \%$. Valores de precipitação pluvial e temperatura média ocorridas durante a condução da pesquisa são apresentados na Figura 1.

A toxicidade dos tratamentos às plantas de milho foi avaliada visualmente aos $7,14 \mathrm{e}$ 28 dias após a aplicação dos tratamentos (DAT), estimando-se notas variando de 0 (zero) a $100 \%$ (cem), em que zero indicou ausência de intoxicação e 100 a morte de todas as plantas de milho. Em se tratando de plantas daninhas, as avaliações de controle foram realizadas aos 14 e 28 DAT, sendo atribuídas notas variando de 0 (zero) (ausência de controle) a $100 \%$ (cem) (controle total da espécie avaliada).

A avaliação de controle da lagarta-docartucho foi feita aos 14 DAT, contando-se o número de plantas da área útil que se apresentavam com as folhas novas raspadas. A colheita do milho foi feita manualmente, e nessa ocasião as seguintes características agronômicas foram avaliadas: estande final de plantas, número de espigas e rendimento de grãos corrigido para $13 \%$ de umidade. A capacidade de expansão (volume/volume) do milho-pipoca foi obtida da razão entre o volume da pipoca expandida e o volume dos grãos.

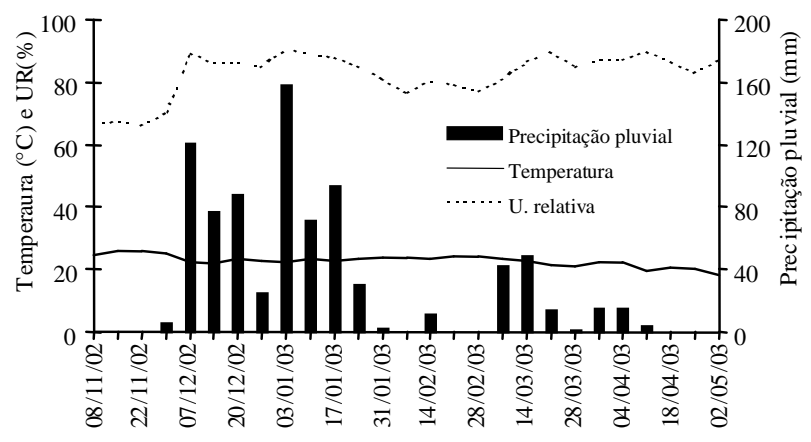

Figura 1 - Valores semanais de precipitação pluvial, temperatura média e umidade relativa do ar média coletadas durante o período de condução do ensaio.
Para cada parcela, foi retirada uma amostra de $60 \mathrm{~mL}$ de grãos, medida em proveta de $100 \mathrm{~mL}$, sendo posteriormente estourada em pipoqueira elétrica. Os grãos foram colocados na câmara de estouro da pipoqueira, quando esta apresentava temperatura de $100{ }^{\circ} \mathrm{C}$, e o volume de pipoca foi medido em proveta graduada.

Os dados foram submetidos à análise de variância e, quando significativos $(p<0,05)$, aplicou-se análise de regressão e/ou comparação das médias dos tratamentos pelo teste de Tukey a $5 \%$ de probabilidade. Na comparação das médias da testemunha com cada média dos tratamentos do fatorial, foi utilizado o teste de Dunnet a 5\% de probabilidade.

\section{RESULTADOS E DISCUSSÃO}

Considerando que o herbicida atrazine em mistura com óleo mineral foi aplicado em todos os tratamentos, admite-se que os efeitos encontrados entre tratamentos sejam devido às doses do nicosulfuron. Dessa forma, observou-se interação significativa entre as doses de nicosulfuron e do chlorpirifos em relação à toxidez dos tratamentos às plantas de milho-pipoca. Os sintomas observados onde o nicosulfuron foi aplicado na ausência do chlorpirifos caracterizaram-se por pequenas manchas estriadas de clorose acompanhando as nervuras das folhas, e por enrugamento nas bordas destas. Nos tratamentos em que o inseticida foi misturado no tanque com os herbicidas, além da clorose, verificou-se paralisação do crescimento das plantas, morte da gema apical e perfilhamento destas. Observou-se, ainda, que os sintomas de intoxicação aumentaram à medida que se elevou a dose de nicosulfuron, em avaliações realizadas aos 7 , 14 e 28 DAT (Tabela 1).

Avaliando o efeito do inseticida nas diferentes doses de nicosulfuron (Tabela 1), verificou-se que, aos 7 e 14 DAT, a presença do chlorpirifos aumentou a intoxicação às plantas de milho, exceto no tratamento em que não se aplicou o nicosulfuron. Aos 28 DAT, observouse recuperação das plantas de milho no tratamento com dose de $10 \mathrm{~g} \mathrm{ha}^{-1}$ de nicosulfuron, não diferindo do tratamento com esta mesma dose, porém sem a presença do inseticida. Observou-se também nessa mesma época de 
Tabela 1 - Toxicidade em plantas de milho-pipoca UFVM2 avaliadas aos 7, 14 e 28 dias após a aplicação dos tratamentos (DAT), em função das doses de nicosulfuron na ausência e presença do chlorpirifos

\begin{tabular}{|c|c|c|c|c|c|c|}
\hline \multirow{2}{*}{ Tratamento } & \multicolumn{5}{|c|}{ Doses de nicosulfuron $\left(\mathrm{g} \mathrm{ha}^{-1}\right)$} & \multirow{2}{*}{ Regressões } \\
\hline & 0,0 & 10 & 20 & 30 & 40 & \\
\hline & \multicolumn{6}{|c|}{$14 \mathrm{DAT}$} \\
\hline Sem chlorpirifos & $0,0 \mathrm{a}$ & $6,75 \mathrm{~b}$ & $8,75 \mathrm{~b}$ & $16,75(+) b$ & $12,75(+) b$ & $\hat{Y}=-0,31+0,797 X-0,011 X^{2}, R^{2}=0,89$ \\
\hline Com chlorpirifos & $0,0 \mathrm{a}$ & $17,5(+) \mathrm{a}$ & $28,75(+) \mathrm{a}$ & $36,25(+) \mathrm{a}$ & $42,5(+) \mathrm{a}$ & $\hat{Y}=0,92+1,601 X-0,0116 X^{2}, R^{2}=0,99$ \\
\hline \multirow[t]{2}{*}{ Testemunha } & 0,0 & - & - & - & - & \\
\hline & \multicolumn{6}{|c|}{$14 \mathrm{DAT}$} \\
\hline Sem chlorpirifos & $0,0 \mathrm{a}$ & $2,0 \mathrm{~b}$ & $5,5 \mathrm{~b}$ & $10,25 \mathrm{~b}$ & $13,75(+) b$ & $\hat{Y}=-0,24+0,236 X-0,003 X^{2}, R^{2}=0,99$ \\
\hline Com chlorpirifos & $0,0 \mathrm{a}$ & $9,25 \mathrm{a}$ & $22,5(+) \mathrm{a}$ & $31,25(+) \mathrm{a}$ & $47,5(+) \mathrm{a}$ & $\hat{Y}=0,05+0,898 X+0,0067 X^{2}, R^{2}=0,99$ \\
\hline \multirow[t]{2}{*}{ Testemunha } & 0,0 & - & - & - & - & \\
\hline & \multicolumn{6}{|c|}{28 DAT } \\
\hline Sem chlorpirifos & $0,0 \mathrm{a}$ & $0,0 \mathrm{a}$ & $0,0 \mathrm{~b}$ & $0,0 \mathrm{~b}$ & $0,0 \mathrm{~b}$ & $\hat{Y}=\bar{Y}=0$ \\
\hline Com chlorpirifos & $0,0 \mathrm{a}$ & $1,25 \mathrm{a}$ & $8,75(+) \mathrm{a}$ & $13,75(+) \mathrm{a}$ & $23,75(+) \mathrm{a}$ & $\hat{Y}=-0,35+0,171 X+0,0107 X^{2}, R^{2}=0,99$ \\
\hline Testemunha & 0,0 & - & - & - & - & \\
\hline
\end{tabular}

As médias seguidas da mesma letra minúscula na coluna não diferem entre si a 5\% de probabilidade pelo teste de Tukey. Já as médias seguidas de (+) foram superiores às das testemunhas pelo teste de Dunnet a $5 \%$ de probabilidade.

avaliação que apenas as três maiores doses de nicosulfuron $\left(20,30\right.$ e $\left.40 \mathrm{~g} \mathrm{ha}^{-1}\right)$ aplicadas em mistura com o inseticida mostraram sintomas de intoxicação superiores aos das testemunhas (Tabela 1).

De acordo com Diehl \& Stoller (1990), a interação entre o nicosulfuron e os inseticidas promove nas plantas de milho uma taxa de metabolismo mais lenta desse herbicida, acarretando menor tolerância ao produto. Quando os herbicidas foram aplicados sem o chlorpirifos, verificou-se, aos 7 e 14 DAT, que a intoxicação às plantas de milho também foi proporcional ao aumento da dose de nicosulfuron (Tabela 1). No entanto, aos $28 \mathrm{DAT}$, independentemente da dose de nicosulfuron, os sintomas desapareceram, evidenciando completa recuperação das plantas de milho quando não se aplica o inseticida (Tabela 1).

Quanto à eficiência de controle de plantas daninhas em todas as épocas avaliadas, não se verificou interação entre as doses de nicosulfuron e as do inseticida chlor pirifos (Figura 3). Considerando o controle das principais espécies daninhas presentes na área após a aplicação dos tratamentos (Bidens pilosa,
Ipomoea grandifolia, Galinsoga parviflora, Artemisia verlotorum, Brachiaria plantaginea $\mathrm{e}$ Brachiaria decumbens), em função das doses de nicosulfuron utilizadas, observou-se que, aos 14 e 28 DAT, todos os tratamentos proporcionaram controle superior a $90 \%$ para I. grandifolia, B. pilosa e G. parviflora (Figura 2). O ótimo controle dessas plantas pode ser atribuído à presença de atrazine + óleo mineral em todos os tratamentos. Todavia, a mistura das diferentes doses de nicosulfuron + atrazine + óleo mineral não foi eficiente no controle de A. verlotorum (<70\%) (Figura 2). Aos $14 \mathrm{e}$ 28 DAT, as três doses mais elevadas de nicosulfuron $\left(20,30\right.$ e $\left.40 \mathrm{~g} \mathrm{ha}^{-1}\right)+$ atrazine + óleo mineral proporcionaram ótimo controle de $B$. plantaginea e $B$. decumbens, e a mistura da dose de $10 \mathrm{~g} \mathrm{ha}^{-1}$ de nicosulfuron com atrazine + óleo mineral, controle entre 80 e $90 \%$ dessas espécies. Esses resultados estão de acordo com Bastiani (1997), que também encontrou baixa eficiência no controle de $A$. verlotorume controle satisfatório de $B$. plantaginea e $B$. decumbens com a utilização do nicosulfuron.

Avaliando o número de plantas e de espigas por tratamento, não se observou interação significativa entre doses de nicosulfuron e chlorpirifos (Tabela 2). Esse resultado pode 

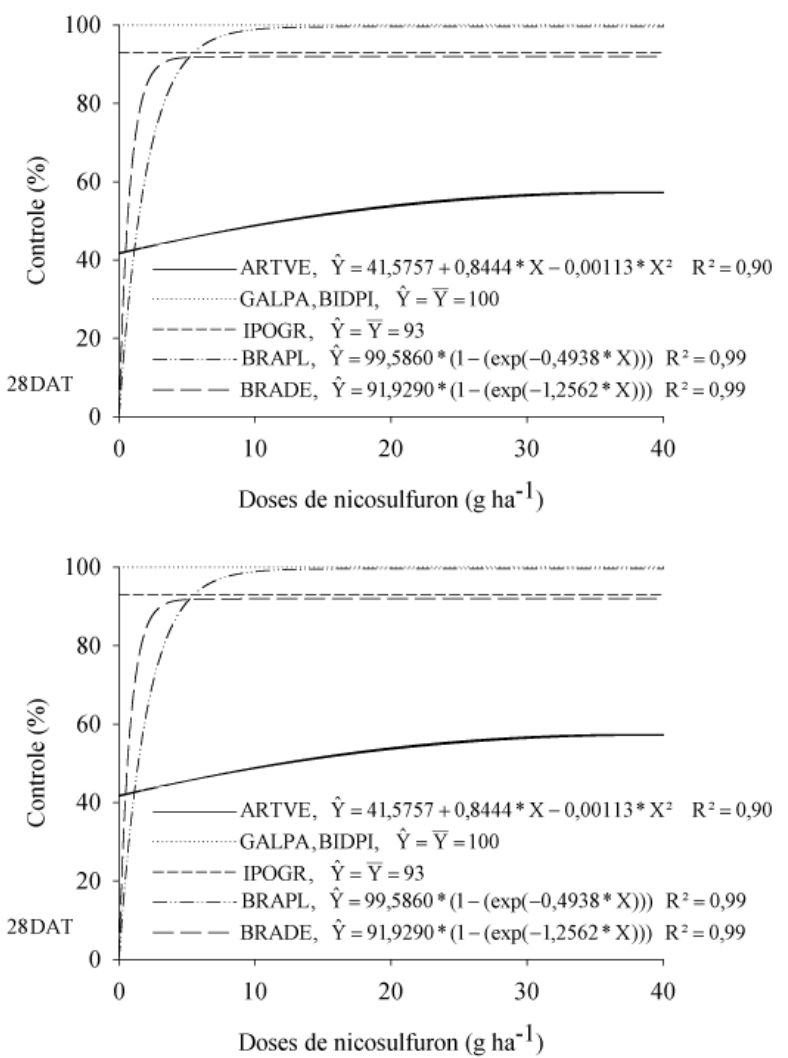

Figura 2 - Controle das plantas daninhas Brachiaria plantaginea (BRAPL), Brachiaria decumbens (BRADE), Artemisia verlotorum (ARTVE), Ipomoea grandifolia (IPOGR), Galinsoga parviflora (GALPA) e Bidens pilosa (BIDPI), em função das doses de nicosulfuron aos 14 e 28 dias após a aplicação dos tratamentos (DAT).

ser explicado pela tolerância do cultivar de milho-pipoca à mistura do nicosulfuron com o chlorpirifos. Quanto ao número de plantas atacadas pela lagarta-do-cartucho, verificouse efeito do inseticida - os tratamentos com chlorpirifos apresentaram menor número de plantas atacadas (Tabela 2).

Quanto à produtividade do milho-pipoca, não se constatou interação significativa entre doses de nicosulfuron e chlorpirifos. No tocante essa característica, verificou-se apenas o efeito significativo para doses de nicosulfuron, sendo então estimada uma única equação de regressão com as médias de cada dose (Tabela 3). Nesse caso, observou-se que a produtividade foi inferior nos tratamentos em que o nicosulfuron não foi aplicado (dose zero), provavelmente pela maior competição do milho com as plantas daninhas, principalmente as monocotiledôneas.
Tabela 2 - Número de plantas (NP), de espigas (NE) e de plantas atacadas pela lagarta-do-cartucho (NPALC) na área útil da parcela, na ausência e na presença do inseticida chlorpirifos

\begin{tabular}{|l|c|c|c|}
\hline \multirow{2}{*}{ Tratamento } & \multicolumn{3}{|c|}{ Característica avaliada } \\
\cline { 2 - 4 } & NP & NE & NPALC \\
\hline Sem chlorpirifos & $64,0 \mathrm{a}$ & $90,5 \mathrm{a}$ & $13,6 \mathrm{a}$ \\
\hline Com chlorpirifos & $68,9 \mathrm{a}$ & $92,1 \mathrm{a}$ & $7,6 \mathrm{~b}$ \\
\hline
\end{tabular}

Médias seguidas da mesma letra na coluna não diferem entre si a 5\% de probabilidade pelo teste de Tukey.

Observou-se que tanto os tratamentos em que o chlorpirifos foi aplicado em mistura com nicosulfuron nas doses de 10, 20, 30 e $40 \mathrm{~g} \mathrm{ha}^{-1}$ quanto aqueles em que o inseticida não foi aplicado não diferiram entre si e entre a testemunha com capina e com chlorpirifos (Tabela 3). Houve diferença apenas entre a dose zero de nicosulfuron e a testemunha com capina, provavelmente pela menor eficiência no controle das gramineas $B$. decumbens e $B$. plantaginea proporcionada apenas pela mistura de atrazine + óleo mineral. Comparando as testemunhas com capina e sem chlorpirifos e capinada com chlorpirifos, não se verificou diferença entre elas, indicando que mesmo onde não se aplicou o inseticida não houve redução de produtividade, em razão do ataque de lagarta-do-cartucho. Isso pode ser explicado pela morte natural das lagartas em decorrência das chuvas ocorridas no período (Figura 1) ou pela baixa infestação observada no campo.

Segundo Kawazaki (2001), a característica que melhor avalia a qualidade da pipoca é a capacidade de expansão dos grãos, quando estourados. Dessa forma, avaliando a capacidade de expansão do cultivar UFVM2, não se verificou interação significativa entre as doses de nicosulfuron e as do chlorpirifos, e também não ocorreram efeitos significativos das doses de nicosulfuron e do inseticida isoladamente, sendo obtido valor médio de 21,56 ( $\left.\mathrm{v} \mathrm{v}^{-1}\right)$.

Em sintese, a presença do chlorpirifos em aplicação isolada, ou em mistura no tanque com nicosulfuron + atrazine + óleo mineral, não interferiu na capacidade de expansão, nos números de plantas e de espigas e na 
Tabela 3 - Produtividade $\left(\mathrm{kg} \mathrm{ha}^{-1}\right)$ do milho-pipoca UFVM2 em função das doses de nicosulfuron, na ausência e na presença do inseticida chlorpirifos e das respectivas testemunhas. Coimbra-MG, 2002/03

\begin{tabular}{|l|c|c|c|c|c|c|}
\hline \multirow{2}{*}{ Tratamento } & \multicolumn{5}{|c|}{ Dose de nicosulfuron $\left(\mathrm{g} \mathrm{ha}^{-1}\right)$} & \multirow{2}{*}{ Regressão } \\
\cline { 2 - 7 } & 0,0 & 10 & 20 & 30 & 40 & \multirow{2}{*}{} \\
\hline $\begin{array}{l}\text { Nicosulfuron sem } \\
\text { chlorpirifos }\end{array}$ & $2483,8(-) \mathrm{aB}$ & $3316,1 \mathrm{aA}$ & $3103,6 \mathrm{aAB}$ & $3133,6 \mathrm{aAB}$ & $3074,1 \mathrm{aAB}$ & $\hat{Y}=2460,93+385,14 X^{0,5}-48,0835 X, R^{2}=0,95$ \\
$\begin{array}{l}\text { Nicosulfuron com } \\
\text { chlorpirifos }\end{array}$ & $2410,0(-) \mathrm{aB}$ & $3257,6 \mathrm{aA}$ & $3161,7 \mathrm{aAB}$ & $3056,7 \mathrm{aAB}$ & $2966,3 \mathrm{aAB}$ & - \\
\hline $\begin{array}{l}\text { Testemunha com } \\
\text { capina sem inseticida }\end{array}$ & 3337,1 & - & - & - & - & - \\
\hline $\begin{array}{l}\text { Testemunha sem } \\
\text { capina sem inseticida }\end{array}$ & $2239,6(-)$ & - & - & - & - & - \\
\hline $\begin{array}{l}\text { Testemunha com } \\
\text { capina com inseticida }\end{array}$ & 3315,6 & - & - & - & - & - \\
\hline
\end{tabular}

Médias seguidas da mesma letra minúscula na coluna ou maiúscula na linha não diferem entre si a 5\% de probabilidade pelo teste de Tukey. Já as médias seguidas de (-) foram inferiores à da testemunha com capina com inseticida pelo teste de Dunnet a 5\% de probabilidade.

produtividade do cultivar UFVM2 de milhopipoca, mesmo com a intoxicação às plantas de milho causada pela adição do chlorpirifos nas maiores doses do nicosulfuron. A eficiência de controle de plantas daninhas pelos herbicidas não foi afetada pela adição do inseticida.

\section{LITERATURA CITADA}

BASTIANI, M. L. R. Atividade dos herbicidas nicosulfuron e atrazine, em condições de casa de vegetação e de campo. 1997. $59 \mathrm{f}$. Tese (Mestrado em Fitotecnia) Universidade Federal de Viçosa, Viçosa, MG, 1997.

BROW, H. M. Mode of action, crop selectivity, and soil relations of the sulfonylurea herbicides. Pestic. Sci., v. 29, p. 263-281, 1990.

DIEHL, K. E.; STOLLER, E. W. Interaction of organophosfate insecticides with nicosulfuron and primisulfuron in corn. Proc. North Cent. Weed Sci., v. 45, p. 31-32, 1990.

FONNE-PFISTER, R. et al. Hydroxilation of primisulfuron inducible cytochrome $\mathrm{P}_{450}$ dependent monooxigenase system from maize. Pestic. Biochem. Physiol., v. 37, n. 1, p. $65-173,1990$.

GUBBIGA, N. G.; WORSHAM, A. D.; OBLE, H. D. Effect of nicosulfuron on johnsongrass (Sorghum halepense) control and corn (Zea mays) performance. Weed Technol., v. 9, p. 3574-3581, 1995.
KAWAZAKI, E. A cultura do milho-pipoca no Brasil. O Agronômico, v. 53, n. 2, 2001. Disponível em: <http:// www.iac.sp.gov.br/new/oagronomico532/11_pipoca.pdf $>$. Acesso em: 2 abr. 2004.

LITHE, R. J. et al. Performance of terbufos on corn rootworm (Coleoptera: Chrysomelidae) in the Corn Belt. J. Econ. Entomol., v. 85, p. 1413-1424, 1992.

MEROTTO, Jr., A. et al. Aumento da população de plantas e uso de herbicidas no controle de plantas daninhas em milho. Planta Daninha, v. 15, n. 2, p. 141-151, 1997.

MORELAND, D. E.; CORBIN, F. T.; McFARLAND, J. E. Effects of safeners on the oxidation of multiple substrates by grain sorghum microsomes. Pestic. Biochem. Physiol., v. 45, p. 43-53, 1993.

PORPIGLIA, P. J.; GILLESPIE, G. R.; JOHNSON, M. D. A method to evaluate the differential response of corn (Zea mays) to sulfonylureas. Weed Sci. Soc. Am. Abstr., p. 61, 1990.

RODRIGUES, B. N.; ALMEIDA, F. L. S. Guia de herbicidas. 5.ed. Londrina: Edição dos autores, 2005. $592 \mathrm{p}$.

STALL, W. M.; BEWICK, T. A. Sweet corn cultivars respond differentially to the herbicide nicosulfuron. Hortscience, v. 27, p. 131-133, 1992.

TRINDADE, F. A. Estudo da tolerância de cultivares de milho-pipoca (Zea mays L.) a herbicidas. 1995. $105 \mathrm{f}$. Dissertação (Mestrado em Fitotecnia) - Universidade Federal de Lavras, Lavras, 1995. 